\title{
APLICABILIDADE DO GERENCIAMENTO DA MUDANÇA DE ENGENHARIA NA TROPICALIZAÇÃO DE UM EQUIPAMENTO INDUSTRIAL
}

\section{APPLICABILITY OF ENGINEERING CHANGE MANAGEMENT ON THE "TROPICALIZATION" OF AN INDUSTRIAL EQUIPMENT}

\author{
Sanderson César Macêdo Barbalho*E-mail: sandersoncesar@unb.br \\ Sérgio Luiz da Silva** E-mail: sergiol.ufscar@gmail.com \\ Marcos Antônio Dias *** E-mail: marcosdias1956@gmail.com \\ Janiele Eduarda S. C. Custódio* E-mail: janielecustodio@gmail.com \\ *Universidade de Brasília (UnB), Brasília, DF \\ ** Universidade Federal de São Carlos (UFSCar), São Carlos, SP \\ ${ }^{* * *}$ Centro Universitário de Araraquara (UNIARA), Araraquara, SP
}

Resumo: O gerenciamento da mudança de engenharia (ECM) é uma prática comum em empresas globalizadas, mas que carece de relatos da sua disseminação em setores mais tradicionais. $O$ presente artigo descreve o desafio encontrado na "tropicalização" de uma tela de centrífuga utilizada na fabricação do açúcar, e os aprendizados daí decorrentes para a mudança de um projeto norteamericano e sua adaptação à realidade brasileira. $O$ método utilizado é o da pesquisa-ação e a abordagem qualitativa. $O$ trabalho contribui ao demonstrar uma aplicação em que o ECM foi adaptado se alinhando ao modelo de negócio da empresa. Os formulários previstos no ECM não burocratizaram o processo, mas passaram servir para formalizar as vendas, engenharia e manufatura do produto. Os resultados conseguidos com o ECM na tropicalização do produto fez com que a técnica passasse a ser utilizada em todas as linhas de produto da empresa no Brasil. Dado que a importação de tecnologias é comum na indústria brasileira, sugere-se que sistemáticas similares aqui apresentada possam ser utilizadas para tropicalizar tecnologias que aumentem sua competitividade.

Palavras-chave: Desenvolvimento de produtos. Gerenciamento da Mudança de Engenharia. Tropicalização. Telas para centrífuga de açúcar. Pesquisa ação.

Abstract: Engineering Change Management (ECM) has been a common practice on global industries. However, this does not match with a compatible number of reports regarding its applications to traditional sectors. This article comes to fill this gap, by describing the challenges faced during the "tropicalization" of a sugar centrifugal screen previously developed in the United States. The work applies a qualitative approach and the action research was the chosen methodology. The ECM framework was adapted to fit the business model and the distinctiveness of the examined company. The forms foreseen in the ECM process were adapted to provide sales, engineering and manufacturing areas with relevant sales information. The positive results of applying the ECM technique encouraged the company to use the methodology on all of its product lines. As imported technologies are common on Brazilian industry, this paper suggests that systematic approaches, as the one presented here, can improve industrial competitiveness.

Keywords: New Product Development. Engineering Change Management. Tropicalization. Sugar Centrifugal Screen. Action Research. 


\section{INTRODUÇÃO}

O Brasil está inserido no comércio internacional como uma economia baseada em commodities. Mesmo assim, o parque industrial do país é referência em diversas áreas.Porém, as inovações de processo, especialmente relacionadas a equipamentos e dispositivos de produção em geral, são desenvolvidas fora do Brasil e são depois comercializadas no país. Ou seja, as fábricas brasileiras buscam absorver as inovações introduzidas no exterior como forma de se manterem competitivas.

A importação de tecnologias é prática comum quando se considera produtos de consumo. Para estes produtos, incorporá-los ao mercado brasileiro implica no máximo em mudanças relativas à legislação. Para produtos de aplicação industrial bens de capital em geral - há toda uma rede de valor estabelecida no país, recursos já investido nos métodos correntes de produção, uma cultura industrial, um perfil de treinamento de operadores e usuários dos equipamentos, enfim todo um contexto mais complexo que requer mudanças e adaptações maiores.

Alguns trabalhos analisam tal contexto sob o enfoque da transferência de tecnologias, tanto analisando o sistema de inovação nacional (VASCONCELLOS e AMATO NETO, 2012), quanto as compras de equipamentos importados em indústrias sujeitas a forte concorrência externa (LUCATO et al. 2015), assim como a transferência de tecnologia de Universidade para empresas (SILVA et al., 2013), e enfim, a tecnologia como conhecimento a ser transferido entre equipes de projeto de produto (FRANK e ECHEVESTE, 2011).

O trabalho de Rodrigues e Estorillo (2012) aborda contexto similar ao do presente artigo no qual uma multinacional brasileira realiza transferência de tecnologia para uma filial mexicana. $O$ autor utiliza um modelo de barreiras à transferência de tecnologias para analisar o caso estudado, o que, entretanto abrange aspectos que extrapolam a engenharia relacionada à tecnologia, pois engloba elementos de logística, regulação de mercado etc., que impactam a construção de plantas industrias. Uma abrangência maior do que a discutida no presente trabalho. Aqui são discutidas implicações do conceito e das técnicas de mudança de engenharia, consolidadas no referencial de Engineering Change 
Management (ECM - Gerenciamento das Mudanças de Engenharia - JARRAT, 2011; ROZENFELD et a., 2006) quando utilizadas para dar suporte à aplicação de um produto de uso industrial desenvolvido no exterior e que foi tropicalizado para uso na indústria brasileira.

As mudanças de engenharia podem consumir entre $33 \%$ e $50 \%$ da capacidade da engenharia (HUANG e MAK, 1998). Para Loch e Terwieschi (1999), as mudanças representam também de $20 \%$ a $50 \%$ dos custos do ferramental utilizado e podem afetar entre $70 \%$ a $80 \%$ o custo final do produto. Dados da indústria alemã (WASMER et al., 2011) mostram que a média do custo unitário das mudanças gira em torno de $€ \$ 20$ mil nas fases de protótipo chegando a $€ \$ 100$ mil depois de iniciada a produção.

O artigo aborda a indústria do açúcar sob o enfoque da aplicação de conceitos de engenharia de produção, algo similar ao proposto por Rebelato, Madaleno e Rodrigues (2012) com enfoque na aplicabilidade do Just in Time e em Paiva e Morabito (2013) referente ao uso de otimização computacional em planejamento agregado da produção. O produto investigado nesse trabalho é uma tela de centrífuga para o processamento de açúcar. A tela, desenvolvida nos Estados Unidos, era aplicada a usinas de açúcar de beterraba e milho. A empresa, com atuação no Brasil em equipamentos para a área de petróleo, viu nesse produto uma oportunidade de diversificar seus negócios no país. Entretanto, quando da implantação da tela nas primeiras usinas canavieiras, foi descoberto que as centrífugas brasileiras tinham geometria diferente das americanas, o que motivou 0 desenvolvimento de iniciativas para adaptar a tela às centrífugas nacionais.

No início, as atividades de adaptação não contavam com um procedimento para que fossem gerenciadas. A empresa não adotou uma sistemática de realizar a mudança e depois vender o produto, o que seria uma abordagem mais alinhada à teoria de ECM (ver ROZENFELD et al., 2006).A mudança, na verdade, se impôs pelos defeitos que o produto apresentava em campo. Assim, como as telas estavam sendo vendidas em paralelo às iniciativas de mudança, um grande fluxo de novos requisitos e necessidades de adaptação do produto surgia e sem uma sistemática de gestão,e assim o ambiente relacionado ao projeto e manufatura do produto se tornava caótico. O caso demonstra portanto uma aplicação diferenciada do ECM, que pode ser usado como aprendizado de referência para outras indústrias que 
recorrem à importação de tecnologias de manufatura para se manterem competitivas.

Assim sendo, o objetivo deste artigo é apresentar uma análise da aplicabilidade de conceitos, técnicas e procedimentos de mudança de engenharia na situação mencionada. O caso expõe como o ferramental de ECM pode ser adaptado de maneira a facilitar as interfaces entre as áreas comercial, de engenharia e de manufatura, e ainda servir como forma de documentação de modelos e configurações de novos produtos desenvolvidos por meio de inovações incrementais. Esse elemento, embora pareça simples, está presente na literatura como uma das dificuldades de aplicação do ECM em função de uma burocratização vinculada com o aspecto documental (HUANG et al. 2003).

A próxima seção apresenta a abordagem metodológica do trabalho. A seguir é discutido o referencial de mudança de engenharia utilizado, posteriormente é descrita a pesquisa ação realizada e enfim, as considerações finais com implicações práticas e teóricas do estudo.

\section{ABORDAGEM METODOLÓGICA EMPREGADA}

A pesquisa-ação foi a abordagem metodológica utilizada na pesquisa dada a oportunidade do trabalho ser realizado em uma situação específica de um processo de importação de tecnologias amplamente utilizado na indústria brasileira. Assim, foi realizado um estudo aprofundado em todos os condicionantes vinculados à pesquisa ação, conforme seu referencial teórico (MIGUEL, 2011). Ou seja, havia um caso bem delineado a ser estudado: a tropicalização de um determinado tipo de tela para centrífugas utilizadas na indústria do açúcar, e adicionalmente, um dos autores do presente artigo esteve envolvido diretamente na mudança de engenharia aqui discutida, conduzindo as ações com os demais participantes da empresa. Considera-se que esse tipo de abordagem participativa é fundamental para que os resultados aqui apresentados sejam conseguidos em aplicações similares.

As atividades utilizadas para a realização da pesquisa-ação foram:

a) Estudo de aspectos teóricos da mudança de engenharia- Por meio da pesquisa bibliográfica foi possível identificar as lacunas para as quais a pesquisa poderia apresentar contribuição científica (MIGUEL 2011). Observou- 
se que não havia trabalhos científicos abordando a temática das contribuições do ECM para a tropicalização, muito embora ações de tropicalização sejam uma realidade muito comum no ambiente industrial brasileiro.

b) Identificação dos procedimentos, atividades, formulários e papéis críticos em um processo genérico de mudança de engenharia - Os principais elementos envolvidos em processos de ECM formais foram sistematizados, sendo descritos na subseção 3.2 .

c) Início da tropicalização do produto - a demanda prática da empresa impulsionou o trabalho inicial de adaptar a tela às condições do ambiente industrial brasileiro. A cultura da empresa apontava para uma metodologia de "tentativa e erro"para tropicalizar o produto. Tal sistemática não foi confrontada pelo pesquisador participante. Optou-se por buscar o entendimento conjunto do problema com os demais atores envolvidos. Essa etapa em certo sentido se deu em paralelo com o estudo teórico do ECM, e à medida que o autor foi se aprofundando no tema e aculturando-o à empresa por meio de reuniões e resolução prática dos problemas com as telas instaladas, começou-se a utilizar conceitos e técnicas do ECM. Houve um momento em que as áreas de vendas, manufatura e engenharia chegaram ao consenso que havia uma demanda por uma ferramenta gerencial e o ECM foi proposto, explicado e aceito. $O$ desafio a partir deste momento foi implantar o ECM fazendo escolhas entre suas múltiplas visões teóricas apresentadas até então.

d) Adoção do processo de mudança - Essa etapa trata da adoção da mudança de engenharia por parte da equipe propriamente dita com a determinação da função de cada participante, as reuniões específicas sobre o assunto e os registros em atas destas reuniões, assim como a elaboração e validação dos formulários e sua sistemática de uso. A proposta de Jarrat (2011) foi utilizada no trabalho como referência para estabelecer um processo de mudança adequado à empresa.É importante ressaltar que a adoção do ECM se deu ao longo do tempo e mediante as etapas apresentadas na subseção 4.2. Também é importante mencionar que tal adoção se deu em paralelo com o processo de resolução de problemas do produto propriamente dito, pois à medida que novos desafios surgiam a técnica proposta era questionada e refinada para dar resposta às demandas do negócio da empresa relacionado ao produto. Enfim, 
o processo apresentado na subseção 4.3 é o resultado de todo o trabalho realizado ao longo da pesquisa ação aqui descrita, partindo-se de um inicialmente proposto que foi sendo modificado para efetivamente dar conta do problema prático da empresa, após diversos ciclos de refinamento.

e) Análise dos elementos críticos do ECM e proposição de elementos à teoria baseados nos experimentos e vivências realizados - uma análise de cada um dos elementos do processo de mudança de engenharia - atividades, formulários, atores etc. - foi realizada, o que é sistematizado na seção 5.Os elementos processuais da mudança de engenharia, assim como o próprio conceito de mudança e sua aplicabilidade no caso de importação de tecnologias para aplicação no Brasil, foram analisados com base na pesquisa ação, o que consta na seção final desse artigo.

Discute-se a seguir o referencial teórico de ECM utilizado no trabalho.

\section{A MUDANÇA DE ENGENHARIA}

Por mudança de engenharia entendem-se modificações na forma, representação, design, formato, material, dimensões, funções, etc., do produto ou componente depois que sua engenharia básica está definida ainda na fase de projetoou quando o produto está em comercialização (HUANG e MAK, 1999; ROUIBAH e CASKEY, 2003). A mudança se inicia com a identificação do seu potencial e é encerrada com a sua implementação na manufatura (WASMER et al., 2011; LOCH e TERWIESCH, 1999).

Empresas caracterizadas por ciclos de vida muito longos para seus produtos, tais como trens, aviões, navios, plataformas de petróleo, linhas de produção, fornecedoras de processos contínuos etc., incorporam as mudanças de engenharia como parte de sua estratégia de produtos, representando sua manutenção e adaptação (SUBRAHMANIAN et al., 2015; MALLICK et al., 2013). As mudanças podem ser vistas não somente como um caminho para corrigir previamente os defeitos, mas também têm um significado de melhoria contínua proporcionando uma agregação de valor às características do produto (MALLICK et al., 2013; WRIGHT, 1997; TERWIESCH e LOCH, 1999). Clark e Fujimoto (1991) apontam a importância das mudanças de engenharia como forma de acelerar o refinamento do produto no 
seu ramp-up na indústria automotiva, enquanto Barbalho, Rojic e Sillos (2012) realizam análise similar em indústria de equipamentos médicos brasileira. Assim, a mudança de engenharia pode acontecer em qualquer fase do ciclo de vida do produto em resposta às necessidades de modificação importantes para sua competitividade.

O gerenciamento das mudanças de engenharia consome tempo e pode ser uma atividade dispendiosa, mas se planejado eficientemente pode se tornar uma vantagem competitiva no que concerne à rapidez e adequação das atualizações do produto ao cliente (MALLICK et al., 2013). Estudos apontam para montadoras automotivas americanas um volume de cerca de 350 mil mudanças por ano a um custo médio de U\$ 50.000,00 cada, enquanto na Alemanha esse número seria de cerca de 1000 mudanças por mês por montadora a um custo de 20-50 mil euros cada (WASMER et al., 2011).

Muitas empresas utilizam uma abordagem baseada em formulários físicos e gerenciamento manual de mudanças (TAVČAR e DUHOVNIK, 2005). Pesquisas realizadas no Reino Unido (HUANG e MAK, 1999) e em Hong Kong (HUANG et al., 2003)identificaram duas abordagens básicas para o ECM: a formal e a ad hoc. A formal se caracteriza por uma sistemática bem definida, através de procedimentos, responsabilidades bem estabelecidas e documentos padrões. A abordagem ad hoc não possui uma sistematização definida. Os autores não chegaram a caracterizar estágios intermediários de adoção do ECM, apenas indicando que a maioria das empresas está entre os dois extremos.

Intensa pesquisa é realizada desde a última década com o intuito de prover ferramentas e métodos para a gestão das mudanças de engenharia. A indústria automotiva alemã estabeleceu consórcio para a criação de ferramenta de gestão de dados de produto compartilhada através de padrão STEP entre montadoras e suas parceiras mais constantes tendo reportado uma redução de 20-40\% no lead-time de processamento das mudanças (WASMER et al., 2011). Ferramentas centradas na rastreabilidade de dados de produto são relatadas em Ouertani et al. (2011), e enfoque na gestão do conhecimento com ferramentas baseadas em ontologias são descritas em Lee et al. (2006). Métodos e ferramentas de suporte a análise de propagação tem sido desenvolvidos com base em abordagens paramétricas 
(ROUIBAH e CASKEY, 2003) ou, mais recentemente, baseadas na árvore de funções do produto (HAMRAZ e CLARKSON, 2015).

\subsection{O processo de mudança de engenharia}

O Quadro 1 apresenta alguns dos autores analisados que apresentam processos de mudança de engenharia.

Quadro 1-Modelos do processo de mudança de Engenharia

\begin{tabular}{|c|c|c|c|c|c|c|c|}
\hline \multicolumn{8}{|c|}{ MODELOS DO PROCESSO DE MUDANÇA DE ENGENHARIA } \\
\hline & $\begin{array}{c}\text { Benedetto } \\
\text { e Trabasso } \\
(1997)\end{array}$ & $\begin{array}{l}\text { Bueno } \\
(2011)\end{array}$ & \begin{tabular}{|c|} 
Horta e \\
Rozenfeld \\
$(\mathbf{2 0 0 2})$
\end{tabular} & \begin{tabular}{c|} 
Rouibahe \\
Caskey, 2003
\end{tabular} & $\begin{array}{l}\text { Rozenfeld et } \\
\text { al. (2006) }\end{array}$ & $\begin{array}{l}\text { Jarrat } \\
(2011)\end{array}$ & Wright (1997) \\
\hline FASE 1 & Encaminhar & Pedido & $\begin{array}{l}\text { Filtrar a } \\
\text { proposta }\end{array}$ & $\begin{array}{l}\text { Definição da } \\
\text { mudança }\end{array}$ & $\begin{array}{l}\text { Identificar } \\
\text { mudança }\end{array}$ & $\begin{array}{c}\text { Solicitar } \\
\text { mudança }\end{array}$ & $\begin{array}{l}\text { Determinação dos } \\
\text { requisitos de cada } \\
\text { componente }\end{array}$ \\
\hline FASE 2 & Autorizar & Aprovação & $\begin{array}{c}\text { Investigar } \\
\text { projeto }\end{array}$ & $\begin{array}{c}\text { Identificação } \\
\text { dos parâmetros } \\
\text { a mudar } \\
\end{array}$ & $\begin{array}{l}\text { Propor } \\
\text { mudança }\end{array}$ & $\begin{array}{c}\text { Identificar } \\
\text { solução }\end{array}$ & $\begin{array}{l}\text { Iniciação de novas ordens } \\
\text { de compra e manufatura }\end{array}$ \\
\hline FASE 3 & Solucionar & $\begin{array}{l}\text { Notificação } \\
\text { / Execução }\end{array}$ & $\begin{array}{l}\text { Avaliar } \\
\text { solução }\end{array}$ & \begin{tabular}{|c|} 
Controle de \\
mudança dos \\
parâmetros \\
\end{tabular} & Alterar & $\begin{array}{l}\text { Avaliar } \\
\text { riscos e } \\
\text { impactos }\end{array}$ & $\begin{array}{c}\text { Cancelamento ou } \\
\text { modificação de ordens } \\
\text { associadas }\end{array}$ \\
\hline FASE 4 & Avaliar & & $\begin{array}{c}\text { Autorizar a } \\
\text { mudança }\end{array}$ & $\begin{array}{l}\text { Auitoria de } \\
\text { parâmetros }\end{array}$ & $\begin{array}{c}\text { Implementar } \\
\text { mudança }\end{array}$ & $\begin{array}{c}\text { Seleção e } \\
\text { aprovação }\end{array}$ & $\begin{array}{l}\text { Aquisição de itens com a } \\
\text { especificação alterada }\end{array}$ \\
\hline FASE 5 & Aprovar & & $\begin{array}{c}\text { Executara } \\
\text { mudança }\end{array}$ & $\begin{array}{l}\text { Registro } \\
\text { histórico da } \\
\text { mudança }\end{array}$ & & $\underset{\text { tação }}{\text { Implemen- }}$ & $\begin{array}{c}\text { Submissão da mudança } \\
\text { para revisão da BOM }\end{array}$ \\
\hline FASE 6 & Liberar & & & & & Revisão & $\begin{array}{l}\text { Coordenação do controle } \\
\text { da produção para } \\
\text { acomodar a mudança } \\
\text { Definição de novos } \\
\text { padrões de custo } \\
\text { Disposição sobre partes } \\
\text { obsoletas } \\
\text { Verificação de todos os } \\
\text { requisitos não contratuais } \\
\text { (manuais etc.) }\end{array}$ \\
\hline
\end{tabular}

Fonte: Autores

Os autores apresentam modelos que têm diferenças entre si. Para comparação será adotado o como base o modelo de Jarrat (2011), uma vez que representa uma visão consolidada pelo Centro de Estudos em Design da Universidade de Cambridge, grupo que vem sistematizando conhecimento em processo, métodos e ferramentas direcionadas à questão das mudanças de 
engenharia. O processo sugerido pelo autor apresenta três macro fases: antes, durante e depois da aprovação.

1. Antes da aprovação: Caracterizada pelas atividades de encaminhar, autorizar, solucionar, avaliar pedido, filtrar a proposta, investigar o projeto, avaliar a solução, propor mudanças, identificar a mudança, solicitar a mudança, identificar a solução, avaliar riscos e impactos. É nesta fase onde ocorrem as principais diferenças entre os estudiosos. Cada autor trata de forma diferente a abordagem do problema. Alguns autores iniciam processos de mudança com a sua identificação e outros sugerem que o início do processo seja com a proposta da mudança encaminhada.

2. Durante a aprovação: Constam atividades de aprovar, notificar, autorizar a mudança, selecionar a mudança a ser realizada. Alguns autores entendem que esta fase faz parte da fase anterior.

3. Depois da aprovação: Consiste em liberar a execução, executar a mudança, executar o projeto, implementar a mudança e revisar.Nessa fase existe um consenso entre os autores.

Os principais envolvidos na mudança de engenharia são: clientes, departamento de vendas e marketing, manutenção, produção, departamento de compras, engenharia de produto, área de qualidade relativa às normas e legislação que impactam o produto. O processo proposto por Jarrat (2011) para a mudança de engenharia é ilustrado na Figura 1. O autor caracteriza quatro pontos de controle do ECP(Engineering Change Process):

1. Ponto 1: O processo tem início na Solicitação de Mudança de Engenharia (ECR). O modo padrão é através de formulário eletrônico ou impresso. solicitante deve preencher o formulário e informar a razão para a mudança, a prioridade da alteração, o tipo de alteração, quais os componentes ou sistemas que podem ou serão afetados. Este formulário é então enviado para um controlador de mudança (Change Manager - CM) que vai inseri-lo num banco de dados da engenharia.

2. Ponto 2: A identificação de possíveis soluções para o pedido de mudança deve então ser investigada. Muitas vezes apenas uma das soluções encontradas é examinada com maior rigor, devido à pressão de tempo ou porque a solução é a mais viável. Alguns autores falam em time de 
mudanças (Change Team - CT) sendo, porém, encontrados apenas em grandes empresas (HUANG e MAK, 1999). Em geral, considera-se que 0 time de mudança é uma estrutura flexível que respeita o escopo de cada mudança e não uma estrutura organizacional fixa.

3. Ponto 3: Os riscos e o impacto da solução são avaliados para cada proposta de mudança. Os fatores que são considerados são: custos, cronograma de produção, o impacto nos fornecedores e os estoques existentes. Essa avaliação pode ser feita pelo time, pelo $\mathrm{CM}$ ou pelo Comitê de Controle de Mudança (CCB), dependendo da empresa (HUANG e MAK, 1999; HUANG et al., 2003).

4. Ponto 4: A partir do momento em que a solução foi selecionada, segue para a aprovação da Engenharia, conselho ou comitê (CCB), que irá analisar a mudança sob a ótica do custo-benefício para a empresa. Os envolvidos são tomadores de decisão ligados ao produto incluindo pessoal de design (projeto / engenharia) do produto, fabricação, comercialização, qualidade, armazenamento, finanças, assistência técnica entre outros. Nesse ponto, se a mudança é aprovada, gera-se uma ECO.

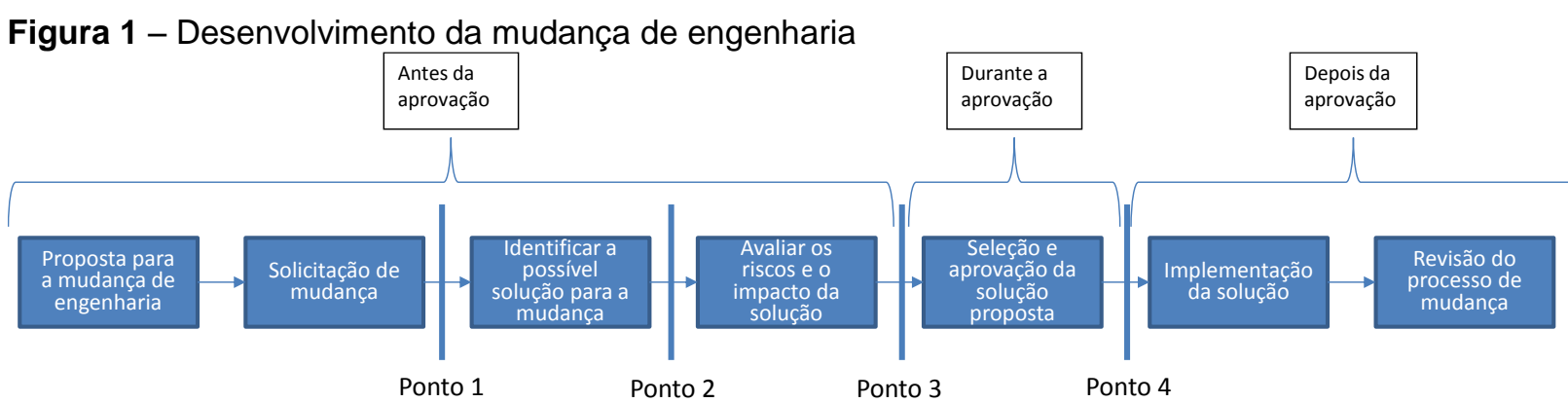

Fonte: JARRAT (2011)

A partir de então, a mudança é realizada, o que deve seguir um fluxo de trabalho controlado conforme o ECM. Ao final, uma revisão deve ser realizada consolidando os resultados da mudança. Isso muitas vezes ocorre em tempo indeterminado, uma vez que cada mudança tem seu tempo de maturação.

Tavcar e Duhovnik (2005) identificaram que a utilização de métodos de engenharia simultânea é um dos elementos que mais influenciam a gestão das mudanças de engenharia em empresas de diferentes setores industriais, o que é 
corroborado pelo estudo de Huang e Mak (1999) que relacionam a adoção do desdobramento da função qualidade (Quality Function Deployment - QFD) com a redução do número de ECR, enquanto o uso do projeto para manufatura e montagem (Design for Manufacture and Assembly - DFMA) está associado à identificação de problemas nos estágios mais iniciais de projeto.

Alguns estudos identificaram as estruturas organizacionais mais fortemente associadas às EC. Observou-se que no Reino Unido as áreas mais fortemente envolvidas nas mudanças são a engenharia, o gerente de mudança e a manufatura (HUANG e MAK, 1999). Estudo realizado em Hong Kong (HUANG et al., 2003) identificou que os CCB ocorrem eventualmente, mas o gerente de mudanças está presente com mais regularidade entre as diferentes empresas estudadas. Em algumas situações, os encontros de mudança - reuniões específicas para discutir EC - tem substituído os CCB.

\subsection{Os elementos da mudança de engenharia}

Os seguintes conceitos compõem os elementos principais do processo de mudança de engenharia considerando os procedimentos mais formalizados apresentados na sessão anterior, reforçados por mais referências científicas, e constituem sua terminologia básica:

a) A Mudança de Engenharia - EC (Engineering Change) utiliza como técnica o Gerenciamento da Mudança de Engenharia, o qual, tomando por base Jarrat (2011) envolve os seguintes elementos:

i. Pedido de mudança - ECR (Engineering Change Request): formulário usado para descrever uma alteração proposta ou problema que pode existir num determinado produto;

ii. Autorização de mudança - ECO (Engineering Change Orders): formulário que preenchido descreve a alteração de engenharia aprovada e a autorização para implementar ou mudar o produto e sua documentação;

b) Change Manager - CM - é quem avalia a viabilidade das ECR, podendo rejeitar, arquivar ou encaminhar para o CCB ou responsável pela mudança. 
c) Configuration Control Board - CCB - Um grupo de partes interessadas responsáveis pelo projeto. Avalia, aprova ou reprova as alterações propostas, prioriza a incorporação de mudanças aprovadas, agenda as mudanças para as próximas versões. O CCB também pode ser responsável por verificar que as mudanças aprovadas sejam implementadas.

d) Processo de mudança - ECP (Engineering Change Process): processo de mudança de engenharia, que pode ocorrer na "fase de desenvolvimento do produto" (BUENO e BORSATO, 2011; BENEDETTO e TRABASSO, 1999; HORTA e ROZENFELD, 2002), somente depois que o produto entrou em operação (WRIGHT, 1997) ou em ambas situações (SUBRAHMANIAN et al., 2015; MALLICK et al., 2013; ROUIBAH e CASKEY, 2003; LI, 2012).

No presente texto, os elementos sistematizados nesta subseção representam o modelo utilizado como referência para estruturar o ECP na empresa. É uma representação abrangente do processo formal de mudança de engenharia, conforme identificado na literatura. Considera-se que tais elementos coadunam as melhores práticas de ECM e, portanto, uma situação ideal a ser implantada no contexto de uma empresa que almeje tropicalizar um produto para o mercado industrial brasileiro.

Os elementos processuais discutidos na contextualização do tema mudança de engenharia e na subseção 3.1 serão utilizados como referencial na pesquisaação realizada. Enfim, o processo ECP proposto por Jarrat (2011) - Figura 1 - foi utilizado para demonstrar o vínculo entre os conceitos de ECM apresentados nesta subseção quando discutida a sua implantação na empresa considerada.

\section{DESCRIÇÃO DA PESQUISA AÇÃO REALIZADA}

O trabalho teve um caráter multidisciplinar, especialmente no que tange à aplicação do ECM no contexto do projeto de máquinas em empresas cuja tecnologia básica - filtragem e separação de componentes - é da engenharia química. De uma maneira geral, empresas que fornecem para o mercado industrial desenvolvem produtos complexos com diferentes áreas da engenharia envolvidas. Neste tópico, 
introduz-se o contexto empresarial, mercadológico e tecnológico do trabalho, e posteriormente a aplicação do ECM.

\subsection{Caracterização da empresa, mercado e tecnologia do produto}

A empresa é uma multinacional do setor de filtração e separação sólido/liquido com matriz e centro de pesquisa e desenvolvimento nos Estados Unidos. Atua na indústria do Petróleo e no início dos anos 90 desenvolveu com sucesso uma tela para centrífugas para usinas de açúcar norte-americanas.

No Brasil, a empresa fez alguns testes para introduzir o produto no início dos anos 2000, mas o custo na época inviabilizava o negócio. Em 2008 retomou a iniciativa.Seu mercado, as usinas de cana brasileiras, utilizava uma tela de níquel, mais comum/usual, de produção nacional.Quando comparada à tela de níquel, o produto da empresa apresenta maior vida útil e tempo médio para a operação de troca de tela igual à anterior tornando-a bastante atrativa para as usinas.

A geometria externa das centrífugas americanas é similar às brasileiras, mas a parte interna tem dimensões diferentes, em geral. No Brasil, a variedade de fabricantes, a exclusividade de sua geometria interna, projetada para diferenciar seu produto dos concorrentes, e as condições operacionais do processo de centrifugação foram parâmetros estudados para definir os elementos necessários à mudança de engenharia.No Brasil, há 12fabricantes, cada um com produto com pequenas diferenciações tornando complexa a introdução da tela americana no Brasil.

Para ilustrar as mudanças realizadas, o Quadro 2 apresenta os principais elementos alterados na tela de origem norte-americana ao longo de três anos de análise totalizando cerca de 70 alterações para adaptar o produto ao contexto nacional. 
Quadro 2 - Parâmetros alterados no projeto inicial para tropicalizar a tela

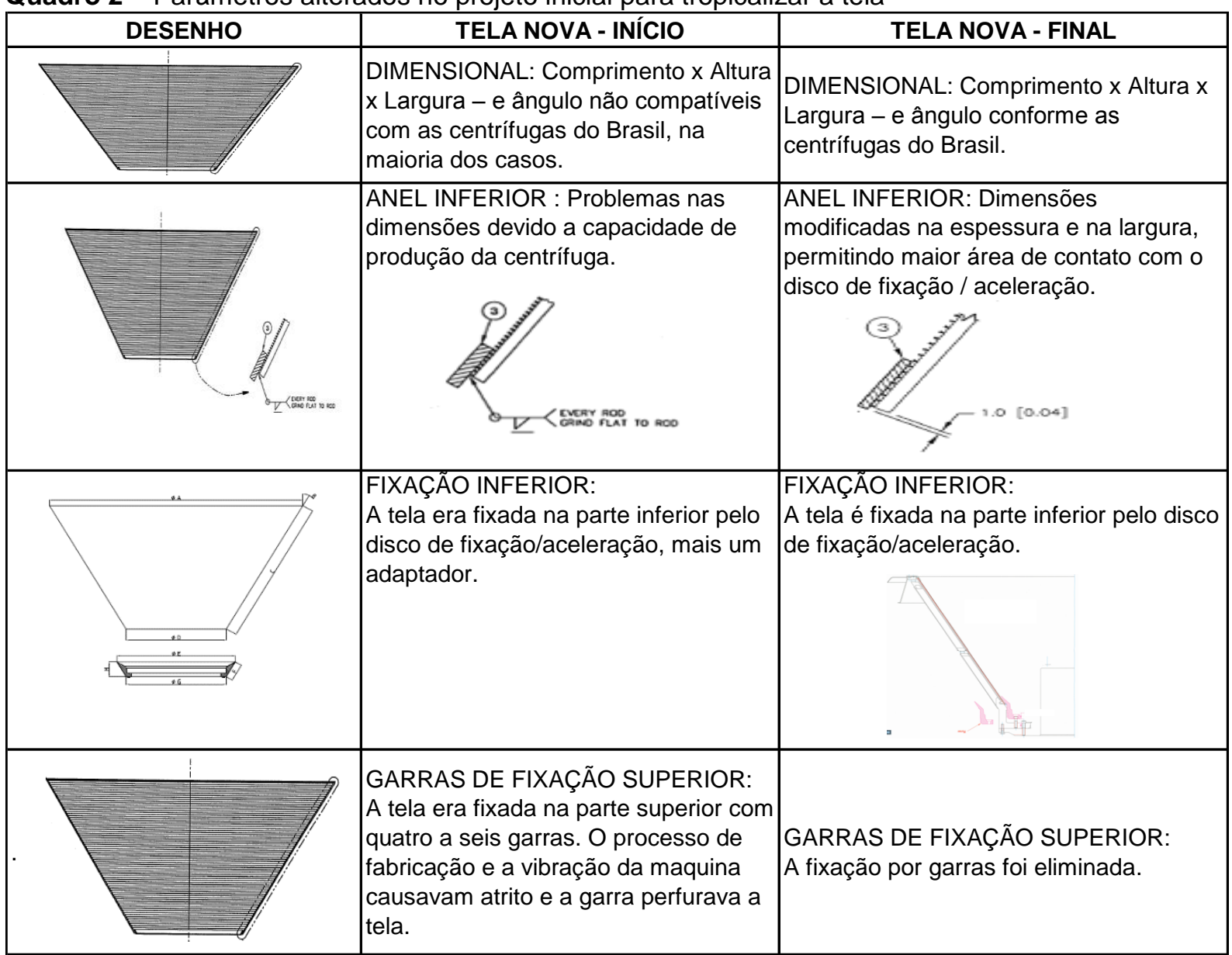

Fonte: Autores

Foge ao escopo do artigo a discussão de cada parâmetro do Quadro 2. Apresenta-se a seguir a evolução da adoção da mudança de engenharia na empresa.

\subsection{Histórico do processo de implantação do ECM na empresa}

A evolução - linha do tempo - da implantação da mudança de engenharia na filial brasileira da empresa em estudo é apresentada na Figura 2. Basicamente, o ECM foi implementado em três fases:

\section{2008 - 2009: Introdução do produto no Brasil}

O cenário econômico apontava para elevado consumo de açúcar e a matriz da empresa fabricante da tela decide trazer seu produto para o Brasil. 0 Brasil é o maior produtor de açúcar de cana e, portanto, o maior mercado 
consumidor de telas. Ocorrem os primeiros problemas com a tela no final de 2009.

\section{2010 - 2011: Antes da implantação do ECM}

Ocorridos os problemas, sua solução era realizada caso a caso, não havendo uma busca sistemática das suas causas raízes. Foi estabelecido um grupo de trabalho coordenado por um técnico da matriz para realizar as mudanças necessárias no produto, porém as alterações eram tratadas informalmente. Verificou-se a necessidade de registrar as mudanças ocorridas, e passou-se a buscar metodologias para fazer com que as áreas envolvidas trocassem informações e mantivessem o histórico da evolução das melhorias. Houve grande resistência da matriz americana em assumir que havia necessidade de alteração no projeto original. Havia uma visão de que a filial brasileira não demandava atividades de engenharia, as quais deveriam ser realizadas integralmente na matriz.

\section{2012 - 2014: Durante a implantação do ECM:}

Esse período é dividido em três etapas:

- 2012 - Início do trabalho com o ECM como oportunidade de melhoria e aprendizado. $O$ autor que participava do processo de implantação do ECM realizou reuniões e palestras para explicar as atividades e formulários necessários à tal sistemática. Foram disponibilizados materiais em português e inglês para os engenheiros, técnicos e gerentes envolvidos nas áreas de vendas, engenharia e manufatura. Apesar disso, houve problemas de interpretação do ECM por parte dos atores das diversas áreas da empresa, especialmente quanto à aplicação prática dos conceitos na empresa. Um momento crítico para a efetiva implantação do ECM foi a criação do CCB e a institucionalização do $\mathrm{CM}$. Foi identificada uma barreira cultural na empresa, pois a gerência geral no Brasil não admitia aplicar uma técnica de "mudança de engenharia" que passasse a impressão de que o projeto americano tinha deficiências. Essa barreira cultural só foi transposta quando ganhou força a idéia de realizar uma "tropicalização" na tela americana em função das especificidades da indústria brasileira, o que de fato era demandado. Mas de 
fato, o ECM foi abordado como um "programa de tropicalização". Em 2012 novas telas já vinham sendo produzidas com todas as modificações necessárias para atender o cliente.

- 2013 - Evolução no entendimento do ECM. A empresa passou a aplicar o ECP para tropicalização da tela com a finalidade de atender ao mercado brasileiro. Diversos ajustes de processo foram realizados, especialmente no uso dos formulários ECR e ECO. No final da safra 2013 a tela tropicalizada foi aprovada pelos principais fabricantes de centrífugas que se tornaram parceiros. É importante mencionar que a condição de falha da tela nova implicava em desconfiança das usinas acerca do padrão de qualidade das centrífugas e quando o conjunto centrífuga - tela nova passou a trabalhar sem falhas, gerou-se uma condição de ganha-ganha para todos os elos da cadeia - usina, multinacional fabricante das telas e fabricantes de centrífugas. A matriz começa a divulgar o novo produto para as filiais em todo o mundo, derivando novas oportunidades de negócios a partir da inovação surgida no Brasil devido à mudança realizada. 
Figura 2 - Evolução do ECM

\begin{tabular}{|c|c|c|c|c|c|c|}
\hline & & & & \multicolumn{3}{|c|}{ FASE 3} \\
\hline & & \multirow{2}{*}{\multicolumn{2}{|c|}{ FASE 2}} & \multirow{4}{*}{$\begin{array}{l}\text { Sucesso do produto. } \\
\text { Aumentou da } \\
\text { demanda. Passou-se } \\
\text { a instalá-lo em } \\
\text { centrífugas } \\
\text { reformadas com } \\
\text { dimensões fora do } \\
\text { padrão. Ajustava-se } \\
\text { o produto caso a } \\
\text { caso, o que } \\
\text { fomentou a } \\
\text { demanda pelo } \\
\text { ECM. Criação do } \\
\text { CCB e do CM. } \\
\text { Dificuldade no } \\
\text { aprendizado do } \\
\text { ECM. }\end{array}$} & \multirow{4}{*}{$\begin{array}{l}\text { Aplicação de } \\
\text { formulários } \\
\text { para } \\
\text { levantamento } \\
\text { de dados e } \\
\text { comparação } \\
\text { com os dados } \\
\text { existentes na } \\
\text { empresa. } \\
\text { Fabricantes de } \\
\text { centrífugas } \\
\text { apresentam } \\
\text { novos } \\
\text { lançamentos. } \\
\text { Evolução no } \\
\text { entendimento } \\
\text { do ECM. }\end{array}$} & \multirow{4}{*}{$\begin{array}{l}\text { Pegar dados dos } \\
\text { novos } \\
\text { lançamentos de } \\
\text { centrífugas e } \\
\text { enviar para } \\
\text { fábrica. } \\
\text { Otimização do } \\
\text { uso do ECM. }\end{array}$} \\
\hline & & & & & & \\
\hline \multicolumn{2}{|c|}{ FASE 1} & \multirow{2}{*}{$\begin{array}{l}\text { Fabricação e } \\
\text { instalação das } \\
\text { seis telas } \\
\text { produzidas no } \\
\text { Brasil. } \\
\text { Problemas na } \\
\text { fixação na parte } \\
\text { superior da tela, } \\
\text { Solução: retirar } \\
\text { as garras de } \\
\text { fixação. Adoção } \\
\text { de novos } \\
\text { dispositivos. }\end{array}$} & \multirow[b]{2}{*}{$\begin{array}{l}\text { Problema: fuga } \\
\text { de cristais pela } \\
\text { parte inferior } \\
\text { da tela. } \\
\text { Solução: Nova } \\
\text { posição para a } \\
\text { chapa de apoio } \\
\text { do disco de } \\
\text { aceleração. } \\
\text { Problema } \\
\text { específico para } \\
\text { centrífugas de } \\
\text { grande } \\
\text { capacidade. }\end{array}$} & & & \\
\hline $\begin{array}{l}\text { Decisão de } \\
\text { investir no } \\
\text { mercado de } \\
\text { açúcar } \\
\text { brasileiro. } \\
\text { Apresentação } \\
\text { do produto às } \\
\text { principais } \\
\text { usinas. }\end{array}$ & $\begin{array}{l}\text { Instalação das } \\
\text { primeiras telas, } \\
\text { uma foi } \\
\text { aprovada a } \\
\text { outra não. } \\
\text { Problemas de } \\
\text { dimensões com } \\
\text { a tela nova. } \\
\text { Resolver caso a } \\
\text { caso. }\end{array}$ & & & & & \\
\hline \multirow[t]{2}{*}{2008} & 2009 & 2010 & 2011 & 2012 & 2013 & 2014 \\
\hline & $\begin{array}{l}\text { Alteração } \\
\text { informal. }\end{array}$ & \begin{tabular}{|l|} 
Alteração \\
informal.
\end{tabular} & $\begin{array}{l}\text { Identificada a } \\
\text { necessidade de } \\
\text { "mudança de } \\
\text { engenharia", sem } \\
\text { entretanto haver } \\
\text { conhecimento ou } \\
\text { adoção de } \\
\text { técnicas e } \\
\text { conceitos mais } \\
\text { sistemáticos. }\end{array}$ & \multicolumn{3}{|c|}{\begin{tabular}{|l|} 
Implantação das técnicas de mudança de engenharia \\
em um programa de tropicalização da tela nova. \\
Uso do formulário de ECR para informar e indicar \\
solução do problema. Analise pelo CCB e CM. Uso do \\
ECO pela área de produção. Arquivamento das ECR e \\
ECO. Base de dados de mudança. Utilizaçãão do ECM \\
para outros produtos da empresa.
\end{tabular}} \\
\hline
\end{tabular}

Fonte: Autores

Revista Produção Online, Florianópolis, SC, v. 16, n. 2, p. 743-753, abr./jun. 2016. 
- 2014 - Nessa etapa, considera-se que o processo de mudança estava robusto na empresa, tendo sido formalizado, utilizando formulários e bases de dados específicas para as mudanças, integradas aos processos de vendas, engenharia e manufatura. Um fato importante para identificar esse nível de robustez foi a facilidade com que a empresa acompanhou os novos lançamentos dos fabricantes de centrífuga nacionais com a realização de ajustes nos desenhos técnicos e processos de fabricação e instalação relacionados às telas adaptadas a tais centrífugas. Criou-se um banco de dados com o dimensionamento das centrífugas instaladas na indústria, e passou-se a utilizá-lo para a construção de telas em centrífugas reformadas e com dimensões fora do padrão.

O processo de mudança utilizado ao final dessa fase 3 é apresentado na próxima seção.

\subsection{O processo da mudança de engenharia aplicado na tropicalização da tela de centrífuga}

O negócio da empresa relacionado às telas de centrífuga é baseado em uma venda técnica. Basicamente, a área comercial vende a tela para o cliente/usuário final, que informa a centrífuga em que será montada a tela. Ocorre que várias centrífugas perderam a condição original por motivos desconhecidos, em função do próprio desgaste por uso ou problemas de manutenção. A maioria dos clientes/usuários não informa ou não sabe desta situação. Assim, há duas condições básicas no negócio: centrífugas que utilizam as telas já padronizadas e as que necessitam de uma tela sob medida, neste caso é necessário conseguir as medidas atuais das centrífugas e verificar a condição de instalação da tela.

Basicamente, o processo construído segue a ilustração da Figura 3, baseada no processo de Jarrat (2011).Como CM foi designado um funcionário com perfil sênior do departamento de engenharia. Ele, em conjunto com uma equipe da engenharia e pessoas chave das áreas de vendas/assistência técnica e manufatura, analisa todas as funções chaves ligadas ao produto: design de produto, fabricação, comercialização, fornecimento, garantia de qualidade, finanças e suporte ao produto. 
Figura 3 - Fluxo da Mudança de Engenharia na empresa

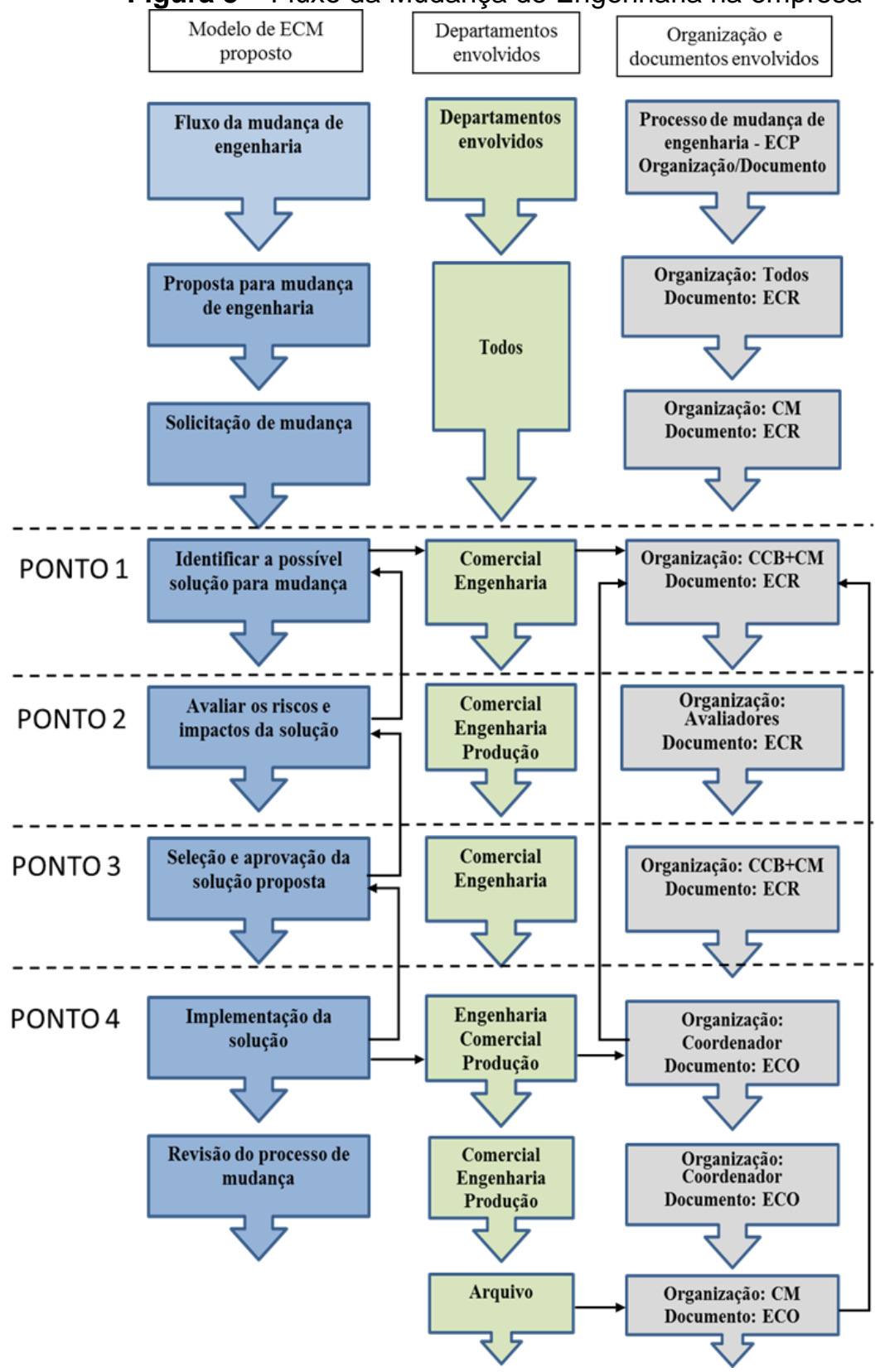

Fonte: Autores

As informações compiladas são levadas pelos CM ao CCB que aprova a solicitação ou requer mais informações da equipe que gerou a solicitação. Identificada a melhor solução, o passo seguinte é verificar qual seu impacto. O CCB é responsável por analisar o impacto da solução. O documento utilizado é o ECR que tem sua origem nas atividades de assistência técnica prévias à instalação da tela em campo. Quando analisado pelo CCB, a solução para o problema específico da instalação já está identificada e proposta pelo CM. O CCB e o CM analisam aspectos do negócio e não exclusivamente da engenharia relacionada à mudança, 
tais como: (1) viabilidade econômica quanto à relação custo-benefício e a margem do produto; (2) cronograma de produção, relacionado ao tempo de obtenção do produto; (3) impacto nos fornecedores e os estoques existentes.

O CCB analisa cada mudança, fazendo uma análise custo-benefício para a empresa como um todo e, em seguida, concede ou não a aprovação para implementação, sendo suas resoluções encaminhadas pelo CM, sendo formalizadas na ECO. Na implementação da solução existe a figura do Coordenador de Produção. Utiliza-se a ECO que traz as informações necessárias para a solução do problema. No caso da tela a ECO trata das alterações e envolve a Produção e Montagem da tela no usuário.

Quanto aos pontos de controle do ECM, tem-se:

1. Ponto 1: A mudança de engenharia passou a ser registrada manualmente, uma vez que o problema era específico para as peças das maquinas utilizadas no Brasil. A solicitação da mudança é feita através do ECR, onde é informado o problema e a solução possível. Todos os departamentos podem criar uma ECR, embora quando relacionado às telas de centrífuga o que mais ocorre é a abertura pelo pessoal de vendas e assistência técnica. As ECR são analisadas pelo CM para verificar se deve-se continuar ou não o processo. Caso positivo é determinado um valor de prioridade para a mudança.

2. Ponto 2: O CM apresenta ao CCB as ECR prioritárias. O CCB avalia os riscos e impactos da solução. O CCB, neste caso, é composto pelos departamentos de Engenharia e Comercial, e também contam com a Engenharia da matriz, caso necessário. No caso do produto aqui descrito, as pessoas - tanto o CM quanto os demais membros do CCB - são fixas, isto é, sempre as mesmas dada a criticidade do processo para o negócio da empresa e a dependência que as mudanças têm com relação ao conhecimento tácito adquirido pelos participantes do CCB ao longo do processo de tropicalização.

3. Ponto 3: $\mathrm{O} C \mathrm{CB}$, em conjunto com o $\mathrm{CM}$, seleciona e aprova a solução para o caso específico. O relatório é anexado à ECR e segue para o quarto ponto.

4. Ponto 4: Neste ponto é criada a ECO pelo CM e, no caso da empresa pesquisada, surge o Coordenador de Produção que vai implementar a Revista Produção Online, Florianópolis, SC, v. 16, n. 2, p. 743-753, abr./jun. 2016. 
solução. A tela é fabricada dentro das especificações que constam na ECO. Após a liberação final pelo Controle de Qualidade o Coordenador de Produção encerra a ECO e entrega para o $\mathrm{CM}$. O CM revisa o processo e arquiva a ECR e a ECO. O CM, adicionalmente, compila os dados da mudança e alimenta o banco de dados relacionado ao produto: cliente, usina, centrífuga, desenhos alterados e alterações relacionadas, mudanças de processo etc.

Um aspecto importante do processo utilizado na empresa é que os formulários foram integrados ao processo de negócio de comercialização das telas de centrífuga. A ECR é compilada com base no relatório de instalação gerado pelo engenheiro ou técnico responsável pela instalação da tela, enquanto a ECO é a folha de processo, considerando tanto fabricação como montagem, do produto para sua perfeita instalação e funcionamento na usina.

Enfim, é importante mencionar que a iniciativa de introduzir o ECP para o caso da tela de centrífuga criou uma demanda organizacional de que o processo fosse usado para todos os produtos comercializados pela empresa no Brasil. Assim, há vários $C C B$ instalados na empresa atualmente, cada um para uma família de produtos.

\section{ANÁLISE DA APLICABILIDADE DOS ELEMENTOS DOGERENCIAMENTO DA MUDANÇA DE ENGENHARIA}

Sumarizando o resultado desta pesquisa e suas implicações em termos técnicos e gerenciais, entende-se o seguinte quanto aos conceitos e técnicas de mudança de engenharia aplicados à indústria sucroalcooleira no caso da fabricante de telas de centrífuga:

1. A Mudança de Engenharia - EC (Engineering Change) - $O$ nome mudança de engenharia não foi bem recebido na empresa. Quando dos primeiros estudos sobre ECM se verificou que se tratava de um caso clássico de mudança de engenharia e se propôs um grupo de trabalho para realizála. Houve forte resistência da gerência, conforme já mencionado.

2. Change Manager - CM - conforme discutido, em 2012 foi instituído um $\mathrm{CM}$, tendo como primeira função organizar as informações sobre o assunto relativo às telas para centrífugas. $\mathrm{O} \mathrm{CM}$ criou um formulário para que as Revista Produção Online, Florianópolis, SC, v. 16, n. 2, p. 743-753, abr./jun. 2016. 
informações seguissem um roteiro padrão. A padronização de grande parte das informações deu origem a um banco de dados, gerenciado também pelo CM. Portanto, o conceito teve forte aplicabilidade no caso aqui apresentado tendo sido amplamente aceito na empresa.

3. Pedido de mudança - ECR (Engineering Change Request): Basicamente, a ECR nasce como um relatório de montagem que além dos campos padronizados, permite anexar fotos e comentários sobre a condição operacional da centrífuga onde será instalada a tela, de forma a subsidiar a mudança de engenharia necessária ao caso. Ela, portanto, deriva de um documento que é usado em todas as instalações de tela apenas agregando maiores detalhes do ambiente de instalação quando o técnico identifica que há necessidades de adequação do produto à situação de uso na usina. A literatura trata a ECR como um documento específico da abertura de mudanças, mas não sugere que ela possa estar vinculada com outras etapas do processo de negócio da empresa. Portanto, considera-se que aqui houve uma adaptação do conceito de ECR ao caso, seja pela dinâmica do negócio de venda técnica e instalação realizada por engenheiro, seja pela necessidade de agilidade nas operações de instalação. Como resultado, os tempos envolvidos na sistematização da solicitação de mudança e na sua análise e implantação na engenharia e na manufatura foram reduzidos.

É importante salientar que no mercado de produtos para a indústria a venda técnica e a necessidade de instalação de produtos é comum, e portanto, o processo de integração entre a ECR e as atividades de venda técnica são passíveis de uso em outros casos similares de produtos tropicalizados.

4. Configuration Control Board - CCB - o CCB foi instituído em 2012, na mesma data do $\mathrm{CM}$ tendo sido fortemente aplicado na empresa garantindo a representatividade das áreas de engenharia e vendas, reduzindo o desgaste relacionado às falhas na instalação das telas e efetivação das vendas. Seu uso foi similar ao descrito na literatura de ECM.

5. Autorização de mudança - ECO (Engineering Change Orders): A autorização de mudança envolve o $\mathrm{CM}$ e $\circ \mathrm{CCB}$, que são as partes interessadas na solução do problema. O ECO formaliza a solução, assim Revista Produção Online, Florianópolis, SC, v. 16, n. 2, p. 743-753, abr./jun. 2016. 
como registra e arquiva os documentos relacionados com a tela alterada. No caso deste estudo quem implanta a solução é um coordenador de produção que faz uso do ECO como uma folha de processo, e posteriormente, como registro de produção e controle de qualidade. Ou seja, O ECO passa a ser fundamental para rastrear cada alteração realizada em cada cliente. Quando comparado com a literatura, o uso do ECO, assim como o da ECR, é diferenciado. Nesse caso também há uma adaptação cujo objetivo é agilizar o processo produtivo e diminuir o volume de documentação gerada. Indiretamente, ao final da manufatura do produto, detalhes de fabricação são consolidados na ECR, uma vez que ela é usada como folha de processo. Tais informações alimentam a base de dados em poder do $\mathrm{CM}$, o que garante a rastreabilidade da mudança e a redução de erros de fabricação e montagem para o caso da mudança em específico.

6. Processo de mudança - ECP (Engineering Change Process): o ECP aplicado à empresa ocorre conforme a literatura.Entretanto, observa-se uma maior integração do ECP com os processos de venda e de manufatura da empresa por meio do uso das ECR e ECO, mencionados acima.

Enfim, o processo de mudança de engenharia utilizado permitiu sistematizar a fabricação das telas de centrífuga, organizar as ações necessárias para customizar as telas e compilar as informações relacionadas a cada cliente, cada centrífuga e cada tela implantada, de maneira a permitir uma gestão integrada das atividades de venda, instalação, engenharia e produção das telas de centrífuga. Adicionalmente, como a documentação para levantamento de informações no campo foi sistematizada, padronizada e inserida num banco de dados, toda vez que chega uma nova solicitação para produção da tela nova, é possível verificar se o projeto já existe ou se haverá necessidade de novo projeto por parte da engenharia e da manufatura. Tal sistemática permitiu uma redução de custo de retrabalhos e de assistência técnica/logística de entrega. Foi possível ainda atuar ativamente na criação de dispositivos para padronização que são usados em todas as famílias de telas para os diversos fabricantes de centrífugas. 


\section{CONSIDERAÇÕES FINAIS}

Apesar de o desenvolvimento e aplicação do conceito de ECM ser mais reportado em indústrias altamente sistematizadas como a espacial, aeronáutica, de defesa e automotiva, verificou-se a viabilidade e contribuição de seu uso em uma indústria com perfil mais tradicional, como a de máquinas e equipamentos.

Observou-se que todos os conceitos de um ECM mais formal se mostraram aplicáveis, tendo sido apenas adaptados como forma de integrar as áreas envolvidas. Assim como a indústria sucroalcooleira, diversos outros setores industriais no Brasil utilizam da importação de tecnologias para modernizar seu parque fabril. Os fornecedores dessas tecnologias muitas vezes têm dificuldade de implantar tais inovações em função de problemas operacionais e de interface do produto com o ambiente e cultura fabril existente. $O$ estudo aqui apresentado demonstra que o ECM pode ser usado efetivamente para mitigar esse tipo de problema.

Adicionalmente, o ECM permitiu algo já consolidado na sua teoria: a sistematização das informações relativas às necessidades de mudança, aquelas já realizadas e as solicitações não atendidas, e especialmente, o porquê de cada situação. Quando compilados tais dados em uma sistema informatizado, e quando designado um gestor dessas informações, no caso o $\mathrm{CM}$, observou-se um aumento efetivo na capacidade de resolução rápida de problemas de mudança vinculados às vendas técnicas que caracterizam esse tipo de ambiente.

Como contribuição tanto científica como prática, ressalta-se no caso o uso da documentação do ECP como suporte a processos mais diretamente relacionados com o fluxo de produção e vendas da empresa. Dessa forma, a burocratização que comumente acompanha a implantação do ECM deixa de ser uma barreira e passa a apresentar um resultado positivo não apenas para o controle das mudanças, mas para a gestão das operações de vendas e manufatura - caso aqui apresentado, para o gerenciamento dos serviços de instalação e para o planejamento do processo de fabricação das telas. Ambiente similar estará relacionado com a introdução de qualquer maquinário fabril importado em uma indústria de processos ou produção em massa abrindo a possibilidade de usar procedimento análogo ao descrito neste artigo. 
Do ponto de vista estritamente científico, o artigo demonstra um tipo de aplicação de ECM diferenciado do encontrado na literatura internacional, corroborando com a sugestão do trabalho seminal de WRIGHT (1997) de que o uso do ECM depende do tipo de negócio no qual a empresa está envolvida. Considerase adicionalmente que quando a empresa vinculou a aplicação do ECM às atividades de instalação, engenharia e manufatura em um contexto Engineering to Order (ETO), o aspecto documental do ECM passou a ser um atrativo da abordagem para $\mathrm{O}$ atendimento das necessidades dos clientes e o conseqüente aumento da carteira de pedidos mitigando o já mencionado problema da burocratização (ver SUBRAHMANIAN et al., 2015), e permitindo a confecção de uma base de dados de engenharia - conforme sugerem diversos estudos - capaz de encurtar os lead-times relacionados à mudança (TERWIESCH e LOCH, 1999). Embora o caso sugira um ganho significativo com as mudanças baseado no uso da base de dados mencionada, considera-se que o uso de um processo altamente integrado ao modelo de negócios impulsionou mais o uso do ECM que a informatização em si.

O termo mudança de engenharia é pouco abordado no mundo corporativo, especialmente nos setores mais tradicionais como o sucroalcooleiro ou agroindustrial, caracterizados por processos contínuos. Considera-se, portanto que 0 tipo de pesquisa aqui relatado poderia ser realizado em outras áreas da indústria no sentido de verificar se, com ajustes e adaptações, o ECM e seus conceitos relacionados poderiam ser utilizados, o que proveria maior formalização aos processos de manufatura e às alterações do produto. Isso porque a informalidade é a realidade encontrada nas indústrias brasileiras e o ECM tem na formalização um dos seus pontos fortes.

Enfim, observou-se que a maior barreira para a implantação do ECM foi o entendimento do conceito de mudança, o qual deve ser considerado mais como oportunidade de melhoria que como problema. Apesar disso, a cultura industrial brasileira, e mesmo a cultura industrial de empresas multinacionais, impõem limitações ao uso da ferramenta. O trabalho aqui apresentado ilustrou uma intervenção de sucesso em que essa barreira foi vencida pela ênfase dada a um "programa de tropicalização" do produto que não denotava um problema de projeto, mas uma necessidade de adaptação da tecnologia ao uso na indústria brasileira. É comum a importação de tecnologias de processo em diversos ramos industriais no Brasil e é comum que os padrões de produtividade almejados não sejam atingidos. Revista Produção Online, Florianópolis, SC, v. 16, n. 2, p. 743-753, abr./jun. 2016. 
O relato apresentado mostra que o gerenciamento da mudança de engenharia pode ser uma abordagem efetiva na identificação e solução de problemas que visem aumentar a produtividade desse tipo de solução.

\section{AGRADECIMENTOS}

Os autores agradecem aos revisores da Revista Produção Online por permitirem, por meio de suas considerações, melhorar significativamente o trabalho final ora apresentado.

\section{REFERÊNCIAS}

BARBALHO, S. C. M.; ROJIC, J.; SILLOS, M. A. Gestão de Configurações e ramp-up de novos produtos: estudo de caso em uma empresa brasileira de base tecnológica.

Produto\&Produção (Online), v. 13, p. 131-147, 2012.

BENEDETTO Neto, H.; TRABASSO, L. G. Identification of factors that affect the ecm engineering change management. In: 12th International Conference on Engineering Design, 1999, Munich: Technische Universität München, 1999. v. 2. pp. 995-1000.

BUENO, M. R.; BORSATO, M. Gerenciamento de mudanças de engenharia: conceitos e tendências. In: 8o. Congresso Brasileiro de Gestão de Desenvolvimento de Produto, 2011, 8., Porto Alegre. Anais... Porto Alegre, 2011.

CLARK, K. B.; FUJIMOTO, T. Product development performance: strategy, organization and management in the world auto industry. Harvard Business School Press, Boston, Massachussets, United States, 1991. http://dx.doi.org/10.1016/0737-6782(92)90078-q

FRANK, A. G.; ECHEVESTE, M. E. Barreiras de transferência de conhecimentos entre projetos de produtos. Revista Produção Online, v.11, n.1, p.29-53,

2011.http://dx.doi.org/10.14488/1676-1901.v11i1.389

HAMRAZ, B.; CLARKSON, P. Industrial evaluation of FBS Linkage - a method to support engineering change management. Journal of Engineering Design, v. 26, n. 1-3, p. 24-47, 2015. http://dx.doi.org/10.1080/09544828.2015.1015783

HUANG, G. Q.; MAK, K. L. Computer aids for engineering change control. Journal of Materials Processing Technology, Vol. 76, pp. 187-191, 1998. http://dx.doi.org/10.1016/s0924-0136(97)00347-6

Current practices of engineering change management in UK manufacturing industries. International Journal of Operations and Production Management, v. 19, n. 1, pp. 21-37, 1999. http://dx.doi.org/10.1108/01443579910244205

HUANG, G; YEE, W.; MAK, K. Current practice of engineering change management in Hong Kong manufacturing industries. Journal of Materials Processing Technology, v. 139, n. 13 SPEC, pp. 481-487, 2003. http://dx.doi.org/10.1016/s0924-0136(03)00524-7 
JARRAT, T. A. W. et al, Engineering change, an overview and perspective on the literature. Research in Engineering Design, v. 22, Issue 2, pp.103 a 124, 2011. http://dx.doi.org/10.1007/s00163-010-0097-y

LEE, H.; AHN, J.; KIM, H.; PARK, J. Capturing and reusing knowledge in engineering change management: A case of automobile development. Information Systems Frontiers, v. 8, n. 5, pp. 375-394, 2006. http://dx.doi.org/10.1007/s10796-006-9009-0

$\mathrm{LI}, \mathrm{W}$. , Modeling and managing engineering changes in a complex product development process, 2012, (Tese de Doutorado em Mecânica e Engenharia Aeroespacial). Syracuse University, Syracuse, p. 206.

$\mathrm{LOCH}, \mathrm{C} . \mathrm{H}$; ; TERWIESCH, C. Accelerating the process of engineering change orders: Capacity and congestion effects. The Journal of Product Innovation Management, v. 16, n. 2, pp. 145-159, 1999. http://dx.doi.org/10.1016/s0737-6782(98)00042-3

LUCATO, W. C. et al. Gerenciamento da transferência internacional de tecnologia: estudo de caso na indústria têxtil brasileira. Revista Gestão e Produção, v. 22, n. 1, p. 213-228, 2015. http://dx.doi.org/10.1590/0104-530x75113

MALLICK, D.; RITZMAN, L.; SINHA, K. Evaluating product-centric continuous improvements: impact on competitive capabilities and business performance. Journal of Product Innovation Management, v. 30, pp. 188-202, 2013.http://dx.doi.org/10.1111/jpim.12071

MIGUEL, P. A. C. (org). Metodologia de pesquisa em engenharia de produção e gestão de operações. 2. ed. Rio de Janeiro, Ed. Elsevier, 2011.

OUERTANI, M.Z.; BAÏNA, S.; GZARA, L.; MOREL, G. Traceability and management of dispersed product knowledge during design and manufacturing. Computer-Aided Design, v. 43. n. 5, pp. 546-562, 2011.http://dx.doi.org/10.1016/i.cad.2010.03.006

HORTA, L.; ROZENFELD, H.; Gerenciamento de mudanças de engenharia: caracterização e estudos de caso. In: 2o Congresso Nacional de Engenharia Mecânica, 2002, João Pessoa. Anais... João Pessoa: ABCM, v. 2, pp. 183-184, 2002.

PAIVA, R. P. O.; MORABITO, R. Otimização do planejamento hierárquico da produção em usinas cooperadas do setor sucroenergético. Revista Produção, v. 23, n. 3, p. 449-467, jul./set. 2013.http://dx.doi.org/10.1590/s0103-65132012005000077

REBELATO, M. G.; MADALENO, L. L.; RODRIGUES, A. M. Um estudo sobre a aplicabilidade do Just in Time na fabricação de etanol. Revista Produção Online, Florianópolis, SC, v.12, n. 3, p. 703-728, jul./set. 2012. http://dx.doi.org/10.14488/16761901.v12i3.967

RODRIGUES, F. R. M.; ESTORILLO, C. Diretrizes para prevenir problemas em processos de transferência de tecnologia: estudo de caso Brasil-México. Revista Produção Online, v.12, n.4, p.944-971, 2012.http://dx.doi.org/10.14488/1676-1901.v12i4.985

ROUIBAH, K.; CASKEY, K. R. Change management in concurrent engineering from a parameter perspective. Computers in Industry, v. 50, n.1, pp. 15-34, 2003.http://dx.doi.org/10.1016/s0166-3615(02)00138-0

ROZENFELD, H. et al. Gestão do desenvolvimento de produtos: uma referência para a melhoria do processo. Editora Saraiva, São Paulo, p. 542, 2006.

Revista Produção Online, Florianópolis, SC, v. 16, n. 2, p. 743-753, abr./jun. 2016. 
SILVA, L. C. S.; KOVALESKI, J. L.; GAIA, S. Gestão do conhecimento organizacional visando à transferência de tecnologia: os desafios enfrentados pelo NIT da Universidade Estadual de Santa Cruz. Revista Produção Online, v.13, n.2, p.677-702, 2013.http://dx.doi.org/10.14488/1676-1901.v13i2.1314

SUBRAHMANIAN, E.; LEE, C.; GRANGER, H. Managing and supporting product life cycle through engineering change management for a complex product. Research in Engineering Design, v. 26, n.3, pp.189-217, 2015.http://dx.doi.org/10.1007/s00163-015-0192-1

TAVČAR, J.; DUHOVNIK, J. Engineering change management in individual and mass production. Robotics and Computer Integrated Manufacturing, v. 21, n. 3, pp. 205-215, 2005. http://dx.doi.org/10.1016/i.rcim.2004.07.017

TERWIESCH, C., \& LOCH, C. Managing the process of engineering change orders: the case of the climate control system in automobile development. Journal of Product Innovation Management, v. 16, n. 2, pp.160-172, 1999.http://dx.doi.org/10.1016/s0737$\underline{6782(98) 00041-1}$

VASCONCELLOS, R. R.; AMATO NETO, J. Fatores críticos na transferência de tecnologia no setor espacial: estudo de caso de programas de parcerias das agências espaciais do Brasil (AEB) e dos EUA (NASA). Revista Produção, v. 22, n. 4, p. 851-864, 2012. http://dx.doi.org/10.1590/s0103-65132012005000062

WASMER, A.; STAUB, G.; VROOM, R. W. An industry approach to shared, crossorganisational engineering change handling - the road towards standards for product data processing. Computer-Aided Design, v. 43. n. 5, p. 533-545, 2011.http://dx.doi.org/10.1016/i.cad.2010.10.002

WRIGHT I.C. A review of research into engineering change management: implications for product design. Design Studies, v. 18, pp. 33-42, 1997. http://dx.doi.org/10.1016/s0142$\underline{694 \times(96) 00029-4}$

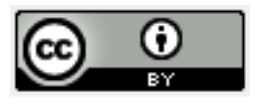

Artigo recebido em 07/10/2015 e aceito para publicação em 06/04/2016 DOI: http://dx.doi.org/ 10.14488/1676-1901.v16i2.2198 